\title{
The Realization of Binary Opposition Joy/Sorrow in Contemporary German Fiction Discourse
}

\author{
Alina Eduardovna Rakhimova ${ }^{1}$, Astrid Vilfridovna Sharipova ${ }^{1}$, Zarema Mukhtarovna Zaripova ${ }^{1}$ \& Guryanov \\ Igor Olegovich $^{1}$ \\ ${ }^{1}$ Kazan (Volga region) Federal University, Kazan, Russian Federation \\ Correspondence: Alina Eduardovna Rakhimova, Kremlevskaya str, 18, Kazan, 420008, Russian Federation
}

Received: February 28, 2015

Accepted: March 20, 2015 Online Published: April 24, 2015

doi:10.5539/res.v7n6p70

URL: http://dx.doi.org/10.5539/res.v7n6p70

\begin{abstract}
The article is devoted to the problems of comparative linguistics, namely the problem of "Joy" and "Sorrow" in the contemporary art discourse. The article deals with the lexemes "Joy"/"Sorrow", representing the binary oppositions. The authors analyze emotive lexemes "Joy"/"Sorrow" based on the works of contemporary German literature, one of the sources of moral categories in human consciousness that provides data on a modern vision of concepts expressed by lexemes "Joy" and "Sorrow". The authors in the article present the interpretation of lexemes in German and Russian, based on the data from representative dictionaries, German and Russian languages, and based on the analysis of artistic works by contemporary German writers cite examples from the original novels, and their Russian translation, it is a comparative analysis of the translations on semantic and linguistic grounds.
\end{abstract}

Keywords: emotive lexicon, lexeme, discourse, verbalization, semantization

\section{Introduction}

Great German linguist L. Weisgerber introduced into scientific terminologythe concept of language picture of the world. According to L. Weisgerber language is the mediator between the objective world and our consciousness, as a kind of creative force in all areas of spiritual and cultural life. Pointing to idioethnical nature of language as a unique tool for understanding the world, which is owned by a particular cultural and spiritual society, L. Weisgerber substantiates the idea common to all speakers of a given society a certain picture of the world, which defines a kind of vision of the world and the continued participation of members of society in the process of cognition.

German scientist Wilhelm von Humboldt argued that language has a decisive influence on the attitudes and perception of the world of man and his way of thinking and emotional sphere. Person interacts with the world around him through the language, who informs him by a certain sign of a picture of the world, which is a result of human understandable and specific reality (Humboldt, 1985).

Pointing to the relationship of language and culture, W. von Humboldt believed that language and culture are forms of human consciousness, which reflect the outlook and perception of the world of man. They coexist in constant close cooperation. The carrier of culture and language is always society, personality, and, therefore, they cannot exist outside of society. Language and culture have inherent contradiction "dynamics—static", language and culture are subjects to certain regulations adopted in this cultural society.

E. Sapir argued that an individual uses the language only for the specific tasks of thinking and communication. A gradual transition of potential values in the reality is made through language, and that allows a person to take up the more conventional understanding of the world.

According to G. V. Kolshanskiy linguistic picture of the world is based on social and working experience of each nation, which finds its expression in the lexical and grammatical diversity of each individual language. Thus, according to G. Kolshanskiy, linguistic picture of the world is nothing, as enshrined in the language of the diversity and creativity of human cognitive activity.

It is a well-known fact that emotions and feelings are something elusive, mysterious and hardly measurable, play an important role in human life. People tend to classify their accumulated experience, then draw some conclusions and generalize this experience. Everything is assessed from the axiological angle, ultimately, it is 
codified. This experience is very important and up to date for each language community. (Ayupova et al., 2014)

As an integral part of our lives in society they have a great influence on a person who loves and hates, rejoices and suffers. Emotion is figurative, complex system of a person that determines his/her behavior and attitude toward the phenomena of reality (Prinz, 2005).

\section{Methodological Part}

The aim of this study is to identify and examine the structure of emotive binary oppositions "Joy"/"Sorrow" and to consider the peculiarities of their functioning in the contemporary literary discourse and to conduct a comparative analysis of the German and Russian languages.

In the study of binary oppositions "Joy"/“Sorrow" in German and Russian artistic discourses descriptive and comparative methods of analysis were used to the languages of different systems defining similarities and differences of lexemes "Joy"/"Sorrow" in German and Russian literary discourse, method of discourse analysis, revealing the contents of the investigated binary oppositions .

The material of research were the examples of literary works by contemporary German writers and their translation into Russian, as well as the data from monolingual and etymological dictionaries of German and Russian languages.

Relevance of research of the chosen theme is that joy and sorrow are among the key lexemes of ethical orientation which characterize man's inner world. For the first time the analysis of data lexemes in works of contemporary German authors reveals both the uniqueness and originality of perception of worldview by the representatives of various lingual cultures.

In modern linguistics, the study of the interrelationship of emotions and language has become more urgent. This is primarily due to the fact that it is impossible to describe the language system adequately, excluding the human emotions and feelings. As an important feature of the lexicon, the category of emotivity displays verbalized emotional reactions in the language, status and relationship of speaking subjects to the world and to themselves in this world (Schwarz, 2007). In modern linguistics there is no universally accepted definition of emotion. German philologists divide all the emotions into two groups: positive and negative, among which are distinguished:

1) Emotions with the help of which people define their attitude to others, for example Love, Hatred, Envy, Compassion;

2) Emotions that occur in certain situations, for example, Care, Joy;

3) Emotions that are a consequence of the reaction to the threat, for example, Fear, Panic;

4) Emotions that are pointed directly to the person, for example, Contrition, Shame, Pride (Schwarz, 2007)

The reflection of the emotions in the word is emotive component, which helps with its verbalization and semantization. Emotive meaning and its implementation in the language can be implemented using various lexemes that create a so-called binary opposition (Jahr, 2000).

\section{Results}

During the study 100 respondents from 24 to 70 years representatives of the native and foreign language culture gave different interpretations of the seme "Joy": the majority of the respondents associate joy with a warm pleasant feeling connected primarily to the welfare of the family (the successes and the health of children, parents), with good and loyal friends, and the priority is the welfare of loved ones. For some joy is pleasant surprises that can give pleasure and lighten the mood.

Modern German literature presents all kinds of joy described in the dictionaries: joy—a feeling of deep-seated and sincere attachment to someone; joy for his neighbor; joy - a feeling of satisfaction.

1) And the man she captured - Grenouille's heart leaped for joy-he was changing at once (Suskind, 2002).

2) They were pleased and happy with each other it was nice to appear in public together (Schlink, 2010).

3) After a while I realized that it is not just about living together but about something more how I imagined a happy life (Schlink, 2010).

4) However she would be happy to buy him new clothes according to the fashion (Schlink, 2010).

In the examples above the lexeme "Joy" refers to the literary and commonly used stylistic layers, because it is neutral and is present in all areas of life the areas of communication and in many functional styles. This vocabulary is usually used in its literal meaning without expressive coloring and denotes habitual actions and the 
human condition. The originality of the neutral vocabulary is in its broad compatibility and combinatory and the ability to be used in expansion contexts.

In the examples given above the value of lexemes of German and Russian languages coincides because they represent such common thing as a state of complete satisfaction with life a feeling of joy. "It is doubtless that the translation of the extracts containing such a device is a challenge to a translator's skills; however, with a certain element of imagination and creativity the Russian translator partially manages to render them into Russian." (Arsenteva \& Kauymova, 2014)

The important and striking techniques of actualization expressions sense of joy its completeness and compatibility with the entity is attributive metaphor and participles which emphasizes the beauty and the sense of joy and transfers it more subtly figuratively and bright.

1) Strictly saying Baldini told him breaking the first attack of joy over the resurrection Grenouille (Suskind, 2002).

2) Exhausted from the divine duties of creation and representation the Great Grenouillewas anticipating domestic joy (Suskind, 2002).

3) And with thieves joy he found that the lipstick he made was much thinner (Suskind, 2002).

4) And his joy was boundless (Suskind, 2002).

5) He liked to sit in the guest chair and sipping a Coke served by waiters (Schlink, 2010)

6) But the next morning — what a tremendous joy was to know that you're live (Schlink, 2010).

7) She said very gently laughing and enjoying our upcoming rendezvous at other times (Schlink, 2010).

Shaped epithets in the examples above-starting, domestic, diebische thieves, original, amazing, borderless, full-demonstrate the strength and depth of joy. It should also be noted that these examples are cognitivepropositional structure comprising three elements: the subject of joy (I, you, he/she/it) — predicate joy (to be/ to have) - signs of joy, which include the above definitions.

Sorrow is the most common valuation concept denoting unfavorable aspects of human life and activity that is the subject to control and overcome. Being the opposite of joy -sorrow is a concept for everything which has a devastating effect on a man in his natural and social manifestations. (Koots et al., 2012)

Referring to the concept of "Sorrow" in German monolingual dictionaries, which give the following definition:

1) Heartache of any loss or misfortune, the official period of mourning after fatal accident;

2) Penitentials (Duden, 2012).

Russian dictionaries meant by seme "Sorrow" state of deep bitterness of soul:

1) Grief, deep sadness;

2) A misfortune;

3) A feeling of sadness, grief (Ozhegov \& Shvedova, 2013).

It should be noted that the lexeme "Sorrow" is much rarer and usually in opposition or relationship with a lexeme "Joy". This is probably due primarily to the fact that the very sense of sadness contradicts with human nature, as people always strive for the best.

Based on the analysis of works of art, we can say that the lexeme "Sorrow" serves to create more vivid and imaginative psychological portrait of the main characters and emotional interpretation and evaluation of the inner world of the writer of fiction text (Selting, 2010).

"The semantic criterion is the most important criterion for forming such micro component of the connotation as expression. If we look through the dictionary we'll find the mark 'expressive' (in Russian), that usually suggests expressive and vivid description of some extra-linguistic reality. Besides there are some intensifiers of meaning, i.e. words or combinations of words (very, absolute, perfect, utterly, etc.) that really intensify the connotation.

We consider it necessary to note that the seme "sorrow" can be attributed to the so-called expressive evaluative vocabulary, emotional tone that defines its subject areas, as it denotes the negative emotions and moods (Shmelev, 2009).

Careful study of the semantic aspect shows that expressivity is most successfully realized and revealed through the context. Such expressive PU's are used for creating figurative picturesque portrayal, or effect of the situation (event) described" (Salieva, 2014). 
In a survey of 100 respondents from different cultures and religion we have found that most people associate seme "Sorrow" with the war, as war is aimed at the destruction of life. For many people, sorrow is a feeling of bitterness at being separated from dearest and nearest, grief and loss. Several respondents believe that sorrow should not be present in our lives, as it is against human nature.

Attributive adjectives, epithets have emotional and evaluative connotations: often - positive (big, huge, bright, true), at least - negative (thieves, jealous).

In modern German literature are represented all interpretations of the lexeme "Sorrow" described in the dictionaries, which is clearly shown by the following examples:

1) She was a stranger to affection, confidence, ability to feel sad about what happened to survive or that was missed, strangers to the indecision and uncertainty (Schlink, 2012).

2) Grief and pain to be endured (Schlink, 2012).

3) I realize that to survive love tragedy—does not mean to jump into the arms of another woman (Schlink, 2012).

4) With sadness thinking about my mother, because her lie not just made us even more strangers to each other, no, she seemed dead to me (Schlink, 2012).

Actualization of lexeme "Sorrow" in contemporary German prose help such predicates as to be, to have, to survive.

From the perspective of a paradigmatics modern German prose presented oppositive paradigmatic relations which are characterized by the formation of word-building chains sorrow, tragedy, sad (adj.), to feel sad and synonymous series grief, sadness, depression, which include words combined with total value of the original item.

1) Former hope and sorrow past suddenly came to life again, if not years have passed, and only a few days (Schlink, 2012).

2) So he probably did not know that sadness, confusion and fear can be a diagnosis which has a name- -who then dreamed about this (Schlink, 2012).

3) He said it with a friendly and sad smile (Schlink, 2012).

4) I read somewhere that the loss of love experiencing about the same time as love itself lasted (Schlink, 2012).

5) He never told me about his depression that tormented him (Schlink, 2012).

Cognitive-propositional structure lexeme "sorrow" includes such items as the subject of grief (he, she, people) - predicate sorrow (have experience, have) - a form of sadness and its characteristics (large, sudden) - cause of grief (loss of love).

By means of actualization of this lexeme are attributive adjectives that are deeper image feelings of sadness, more comprehensive and penetrating pain from of momentary grief: a large, unexpected and unfair.

Although the words of this style are characterized by the absence of expressive color, but this does not mean that the vocabulary of this level cannot participate in the expression of subjective modality, emotional and expressive nuances of speech. Expressiveness of stylistically neutral, common words lies in their potential, which can be detected according to context (Rahimova, 2013). In particular, the lexeme "joy" refers to certain emotions and experiences, has emotional and estimated value. In fact the lexical meaning of the word is a certain score designated events. Such specificity of neutral vocabulary determines its broad compatibility and the ability to be used in a figurative sense.

Universal for studied linguocultures is:

1) Exposure of joy to "reification", transformation from abstract to concrete concept, as a result you can receive, present, lose or keep it;

2) The ability of joy to create the volume of the external world around the subject;

3) Liability to personification of joy, as a result it acquires the ability to perform certain actions, inherent to living being (come to accompany someone);

4) Dependence of the joy on the forces applied by the person to achieve it (Brandes, 2014).

It should also be noted that "not all of the synonyms found in the Russian translation; however, all the counterparts given are synonyms and all of them are informal" (Arsenteva \& Kayumova, 2014). On the paradigmatic level lexical paradigm can be observed when a so-called derivational chain (joy, sharing the joy, 
rejoice and synonymous lines that include vocabulary, indicating emotions and feelings (joyful, cheerful, happy). This kind of relationship is called paradigmatic opposition in which there is the relationship between the invariants - the various functional units of one language level. It seems necessary to show by example.

1) It was like a muffled: that was how they enjoyed each other their jokes and laughter they talked about everything in this world (Schlink, 2010).

2) He and she - fellow sufferers and maybe vice versa they shared a common joy (Koots et al., 2012).

3) On the night I enjoyed listening to the rain, I enjoyed watching the rain out the window of my office that made getting more comfortable (Schlink, 2010).

4) Mother so willingly went on this trip that sometimes I even seemed perpetual expression inaccessibility and contempt vanished from her face (Schlink, 2010).

5) Are you glad that your search is over (Schlink, 2010).

6) Because there are deceivers cute and unsympathetic, moral and immoral, funny and sad (Schlink, 2010).

\section{Discussion}

The theme of joy and sorrow has often been subject of many ancient philosophers, who wrote about the unearthly (supernatural) joy which all people should aspire to and deep sorrow that befall to everyone who will live in spite of moral norms and laws. Such attention to the joys and sorrows by scientists proves that the concepts of joy and sorrow belong to the main categories of culture that are at the center of national and individual consciousness and attitude towards them characterizes the spiritual essence of man. Linguo cultural emotional lexemes "joy" and "sorrow" are complex mental formations, which have linguistic expression and marked ethnic and cultural characteristics. The lexemes under study have different set of features, entering into a relationship of binary opposition and realized both on the language and on the discursive level. By virtue of its ethnic and cultural features of these lexemes distinctly receive treatment in the context of different cultures (Wierzbicka, 1999). Our scientific interest is directed to implement them in two cultures: German and Russian.

Philosophical tradition and joy of everyday consciousness is identified with the state of emotional well-being, the clemency of fate and a large spiritual satisfaction.

By combining the interpretation of the seme "Joy" (the dictionaries of the German language give the following definition of the word "Joy": 1) Good mood; to be joyful and happy; 2) Smth that makes someone happy (Duden: 2012).

Monolingual Russian dictionaries give similar treatment of the seme "joy": 1) A fun feeling, feeling of great spiritual satisfaction, a feeling of pleasure; 2) What (who) causes a feeling of pleasure, gives happiness; 3) Joyful happy event, circumstance; 4) Affectionate, gentle treatment (Ozhegov \& Shvedova, 2013).

In our study we use the following interpretation of the lexeme: "A separate unit of meaning usually in the form of a word, but also as a group of words" given by H. G. Widdowson (Widdowson, 2009). Thus we can conclude that the semantics of lexemes "Joy" in German and Russian languages correspond partly on the grounds, however, it should be noted that the Russian word joy characterizes deeper and more emotional state of mind in contrast to the German seme "Joy", which is characterized by restraint and frugality of the language.

\section{Conclusion}

In modern studies, linguistic picture of the world is inextricably linked with culture, as it is nothing but the reflection in the mind of his world, as well as its cultural, spiritual, social and physical experience. Language picture of the world has attributes that are different in different nations, due to some differences in beliefs, traditions, and lifestyle.

Thus, summing up the above, it can be argued that the language picture of the world, reflecting the reality by means of language, verbalizes it makes fuller, richer and deeper, passing from generation to generation language, national and cultural experience. The analysis of contemporary German prose suggests that the lexemes "Joy" and the "Sorrow" representing a binary opposition have certain universal and specific features. It should also be noted that these lexemes can be attributed to the estimated-expressive vocabulary because they have emotional and valuation characteristics. Emotive coloring of considered lexemes is defined by their subject areas because they represent different emotions, feelings and moods.

Thus, the results of our study can be concluded that the lexeme "Joy" and the "Sorrow" in contemporary German prose presented in such spheres of life, such as family, career, statehood, politics. It was found that the lexeme "Sorrow" is much rarer due to its semantics. 
In the comparative analysis of word interpretations of lexemes "Joy" and the "Sorrow" showed that the meanings of lexemes in German and Russian languages are basically the same but it should be noted that the semantics of German lexemes is wider and more different emotionality.

Observations on literary texts proved sufficient similarity in understanding the joys and sorrows and methods of verbal expression in the German and Russian linguo cultures.

The results of the study can serve as a basis for psycholinguistic projects to study the features of mental fields. In addition, it will contribute to the study of the peculiarities of attitude, outlook and perception of the world by the person and to trace the influence of national customs, ethical, aesthetic and religious principles.

It should also be noted that this problem has a significant potential for further research in the framework of comparative linguistics. In particular, these lexemes can be considered in languages with different structures, since they are the basic emotive categories found in different linguistic cultures. In future comparative study of data lexemes as concepts and identification of near and far periphery, as well as lexical and grammatical differences in the use of these concepts in languages of different systems. An interesting question is the frequency of use of these lexemes, not only in fiction but also in other types of discourse, such as political.

This topic provides a wide field for the linguistic-cultural experiment to identify linguistic features of perception of data emotive lexemes by representatives of various social, cultural and linguistic groups.

\section{References}

Arsenteva, E. F., \& Kayumova, A. R. (2014). Complex modifications of phraseological units and the ways of their translation. Life Science Journal, 11, 502-506.

Ayupova, R. A, Bashirova, M. A., Bezuglova, O. A., Kuznetsova, A. A., \& Sakhibullina, K. A. (2014). Ornythonym component and phraseological meaning. Life Science Journal, 11, 290-293.

Brandes, M. P. (2014). Text stylistics. M: ID KDU.

Duden German Universal Dictionary. (2012). Mannheim: Dudenverlag.

Humboldt, V. (1985). Language and cultural philosophy. Moscow: Progress.

Jahr, S. (2000). Feelings and Emotions structures in expository texts. Berlin: Walter de Gruyter.

Koots, L., Realo, A., \& Allik, J. (2012). Relationship between Linguistic Antonyms in Momentary and Retrospective Ratings of Happiness and Sadness. Journal of Individual Differences, 33, 43-53. http://dx.doi.org/10.1027/1614-0001/a000061

Ozhegov, S. I., \& Shvedova, N. U. (2013). Dictionary of Russian language. Moscow: A TEMP.

Prinz, J. (2005). Are emotions feelings? Journal of Consciousness Studies, 12, 8-10.

Rakhimova, A. (2013). Realisation of binary opposition "Love"/"Hate" in the modern world of the German language picture of the ethnic group. Philology and Culture, 34(4), 109-114.

Salieva, R. N. (2014). Phraseology in Multilingual society: Phraseological units with onomatopoeic component and transparent inner form. Cambridge Scholars Publishing.

Schlink, B. (2010). Return (A. Belobratov, Trans.). St. Petersburg: ABC-classic.

Schlink, B. (2012). Summer lies. Zurich: Diogenes Verlag.

Schwarz-Friesel, M. (2007). Language and Emotion. Stuttgart: UTB.

Schwarz-Friesel, M. (2007). Language, Cognition and Emotion: New Directions in Cognitive Science. In Language-cognition-culture (pp. 277-301).

Selting, M. (2010). Affective in conversational storytelling: An analysis of displays of anger or indignation in complaint stories. Pragmatics, 20(2), 229-277. http://dx.doi.org/10.1075/prag.20.2.06sel

Shmelev, D. N. (2009). Modern Russian language: Lexics. Moscow: Librocom.

Suskind, P. (2002). Perfumer. In Story of a Murderer (E. Vengerov, Trans.). St. Petersburg: ABC-Classical.

Widdowson, H. G. (2009). Linguistics. Oxford University press.

Wierzbicka, A. (1999). Emotions across languages and cultures. In Diversity and universals. Cambridge: Cambridge University Press. http://dx.doi.org/10.1017/CBO9780511521256 


\section{Copyrights}

Copyright for this article is retained by the author(s), with first publication rights granted to the journal.

This is an open-access article distributed under the terms and conditions of the Creative Commons Attribution license (http://creativecommons.org/licenses/by/3.0/). 